\begin{tabular}{|c|c|}
\hline Title: & $\begin{array}{l}\text { Loss Comparison of Small Delta- and Star-Connected Permanent Magnet Synchronous } \\
\text { Machines }\end{array}$ \\
\hline Authors: & Felix Rehm, Patrick Breining, Simon Decker, Johannes Kolb, Marc Hiller \\
\hline Institute: & $\begin{array}{l}\text { Karlsruhe Institute of Technology (KIT) } \\
\text { Institute of Electrical Engineering (ETI) } \\
\text { Power Electronic Systems (PES) }\end{array}$ \\
\hline Type: & Conference Proceedings \\
\hline Published at: & $\begin{array}{l}\text { Proceedings IECON } 2019 \text { - 45th Annual Conference of the IEEE Industrial Electronics } \\
\text { Society } \\
\text { Publisher: IEEE } \\
\text { Year: } 2019 \\
\text { ISBN: } 978-1-7281-4878-6 \\
\text { Pages: } 1171-1176\end{array}$ \\
\hline Hyperlinks: & https://ieeexplore.ieee.org/document/8927165 \\
\hline
\end{tabular}

(C) 2019 IEEE. Personal use of this material is permitted. Permission from IEEE must be obtained for all other uses, in any current or future media, including reprinting/republishing this material for advertising or promotional purposes, creating new collective works, for resale or redistribution to servers or lists, or reuse of any copyrighted component of this work in other works. 


\title{
Loss Comparison of Small Delta- and Star-Connected Permanent Magnet Synchronous Machines
}

\author{
Felix Rehm ${ }^{1 *}$, Patrick Breining ${ }^{1}$, Simon Decker ${ }^{1}$, Johannes Kolb ${ }^{2}$ and Marc Hiller ${ }^{1}$ \\ ${ }^{1}$ Institute of Electrical Engineering, Karlsruhe Institute of Technology, Karlsruhe, Germany \\ ${ }^{2}$ SHARE at KIT, Schaeffler Technologies AG \& Co. KG, Karlsruhe, Germany \\ *E-mail: felix.rehm@kit.edu
}

\begin{abstract}
Delta-connected stator windings are often used in mass production of small Permanent Magnet Synchronous Machines (PMSMs). In comparison to star-connected stator windings, a delta-connected winding system offers advantages for manufacturing and lowers production costs. A main disadvantage of motors with such a winding system are additional losses caused by the Zero-Sequence Current Component (ZSCC). In this paper the ZSCC and its impact on the generated losses in a deltaconnected PMSM used as a traction motor for a pedal electric cycle (Pedelec) is analysed. The calculated results are compared to those of a star-connected PMSM with the same design. We will show that the amplitude of the ZSCC depends on the operating point of the machine. As a result, the copper losses in the deltaconnected machine are up to $5.8 \%$ higher than the ones in the star-connected machine. On the other hand, the iron losses are $1 \%$ smaller in the delta-connected machine. The efficiency of the delta-connected machine is still up to $4 \%$ smaller.

Index Terms-delta connection, zero-sequence current component, loss comparison, pedal electric cycle
\end{abstract}

\section{INTRODUCTION}

In the past years, the demand for small electrical motors is continuously growing, as they are increasingly used within mobile equipment, such as drones, quadcopters, electric scooters or pedal electric cycles (Pedelecs). Due to a high power density and a high efficiency, Permanent Magnet Synchronous Machines (PMSMs) are commonly used.

Even though their purpose of application is different, the majority of these machines need to be manufactured at similar conditions, as the production of high quantities demands low manufacturing costs. Manufacturing costs can be kept low through automated process steps, which is why concentrated windings are often used. The costs can be further reduced, by using a delta-connected winding system. For this winding system no star-point connector is needed, which saves material and reduces the number of process steps during manufacturing. Therefore, delta-connected stator windings are well suited for mass production with a high demand on automated manufacturing and low costs [1].

A main disadvantage of delta-connected PMSMs are additional losses caused by the Zero-Sequence Current Component (ZSCC), which can result in a circular current as depicted in Fig. 1. A ZSCC is caused by imbalances between single motor phases or parallel coils. Manufacturing tolerances, which exemplarily result in a variance of magnetization of

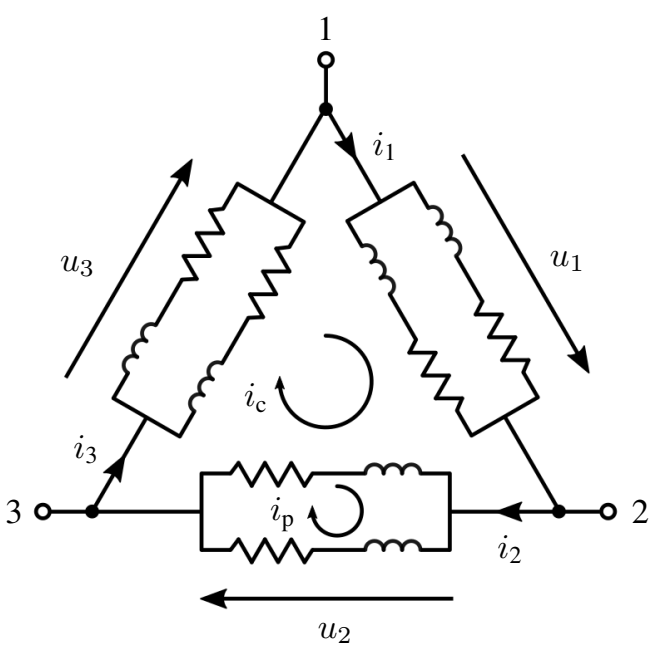

Fig. 1. Delta-connected stator windings.

permanent magnets or in rotor eccentricities, are a main reason for electromagnetic and mechanical imbalances [2]. Besides manufacturing tolerances, iron saturation is another reason for electromagnetic imbalances. Due to iron saturation circulating currents of order $n \cdot m$ occur, where $n$ is a natural number and $m$ the number of phases [3].

Detailed knowledge about the ZSCC is useful as it helps to detect demagnetization faults during machine operation. Therefore, the authors of [4] suggest comparing the amplitude of the ZSCC under healthy and faulty conditions. In [5] a delta- and a star-connected PMSM with the same design in the use case as a wheel hub drive are compared. To evaluate the additional copper losses in the delta-connected machine, the ZSCC is investigated under no-load operation of the motor. In [1] circulating currents in a delta-connected machine due to manufacturing tolerances, iron saturation as well as asymmetrical load conditions, are discussed. The authors conclude that electrical and mechanical tolerances have a big impact on circulating currents. However, the ZSCC is only investigated for single operating points and saturation levels. The fact that the ZSCC depends on the level of saturation is shown in [6] for delta- and star-connected squirrel cage induction machines. Measurements show that an increase of $14 \%$ in the 
magnetizing flux above the rated value leads to an increase of $108 \%$ in the RMS value of the ZSCC.

Because of the aforementioned, this paper focuses on a quantitative analysis of generated losses in the operating range of a PMSM used as a traction motor for Pedelecs in dependence of the ZSCC. For better comparability, we investigate a delta-connected machine and a star-connected machine with same design.

\section{THEORY}

In the stationary reference frame the voltage equation for each motor phase of a three-phase machine is given by

$$
\begin{aligned}
& v_{1}=R_{1} \cdot i_{1}+\frac{\mathrm{d} \psi_{1}}{\mathrm{~d} t}, \\
& v_{2}=R_{2} \cdot i_{2}+\frac{\mathrm{d} \psi_{2}}{\mathrm{~d} t}, \\
& v_{3}=R_{3} \cdot i_{3}+\frac{\mathrm{d} \psi_{3}}{\mathrm{~d} t},
\end{aligned}
$$

where $v_{x}$ describes the phase voltage, $R_{x}$ the phase resistance, $i_{x}$ the phase current and $\psi_{x}$ the flux linkage with $x \in\{1,2,3\}$ [7]. Assuming the same electrical resistance for each motor phase one gets $R=R_{1}=R_{2}=R_{3}$.

Applying Park's transformation to (1) - (3) leads to voltage equations in the rotating reference frame (dq0-frame). In the dq0-frame, the d-axis is aligned with the direction of the rotor flux. The q-axis is phase shifted by 90 degrees electrical to the $\mathrm{d}$-axis. Consequently, in the dq0-frame the voltage equations of a PMSM are given by

$$
\begin{aligned}
& v_{\mathrm{d}}=R \cdot i_{\mathrm{d}}+\frac{\mathrm{d} \psi_{\mathrm{d}}}{\mathrm{d} t}-\omega \psi_{\mathrm{q}}, \\
& v_{\mathrm{q}}=R \cdot i_{\mathrm{q}}+\frac{\mathrm{d} \psi_{\mathrm{q}}}{\mathrm{d} t}+\omega \psi_{\mathrm{d}}, \\
& v_{0}=R \cdot i_{0}+\frac{\mathrm{d} \psi_{0}}{\mathrm{~d} t},
\end{aligned}
$$

where $v_{x}$ describes the voltage, $R$ the phase resistance, $i_{x}$ the current, $\psi_{x}$ the flux linkage with $x \in\{\mathrm{d}, \mathrm{q}, 0\}$ and $\omega$ the electrical angular velocity [3]. For a three-phase PMSM the zero-sequence components are defined as

$$
x_{0}=\frac{1}{3} \cdot\left(x_{1}+x_{2}+x_{3}\right)
$$

where $x_{1}, x_{2}$ and $x_{3}$ correspond to each motor phase with $x \in\{v, i, \psi\}$.

If there is no neutral connection at the star point, (6) can be simplified as followed for star-connected PMSMs

$$
v_{0}=\frac{\mathrm{d} \psi_{0}}{\mathrm{~d} t}
$$

as the sum of the phase currents $i_{1}, i_{2}$ and $i_{3}$ equals zero at every point in time. Equation (8) shows that a time-varying zero-sequence flux linkage component leads to a voltage different from zero at the star-point connector towards ground. If parasitic capacities are small enough, a zero-sequence voltage component does not lead to a ZSCC or to additional magnetic fields. Therefore, the fundamental characteristic of a threephase machine can be expressed by (4) and (5).
For delta-connected PMSMs, (6) can be simplified to

$$
i_{0}=-\frac{1}{R} \cdot \frac{\mathrm{d} \psi_{0}}{\mathrm{~d} t}
$$

as the sum of the phase voltages $v_{1}, v_{2}$ and $v_{3}$ equals zero at every point in time. A time-varying zero-sequence flux linkage component causes a ZSCC. Mostly the zerosequence components are neglected, as they do not produce any electromagnetic torque. For the calculation of losses, the zero-sequence components have to be regarded, as the ZSCC causes additional copper losses. Because of cross-coupling effects in highly saturated machines, an influence of the ZSCC on the flux linkages in d- and q-axis can be expected. Due to Lenz's law, the magnetic field caused by the ZSCC lowers the zero-sequence flux linkage component and therefore also the level of magnetic saturation in the machine.

\section{Machine Under Study And Simulation Setup}

\section{A. Machine Under Study}

Fig. 2 shows half of the cross section of the analysed machine. Its stator has 18 slots with a double-layer concentrated winding. The number of parallel paths per phase is two. The magnet arrangement in the 14-pole spoke-type rotor results in a flux-concentration and therefore leads to an increased air-gap flux density compared to surface-mounted PMSMs [8]. The rotor poles are shaped such that the torque ripple, cogging torque and harmonics within the electromotive force (EMF) are reduced [9]. Table I lists the main geometry and machine parameters.

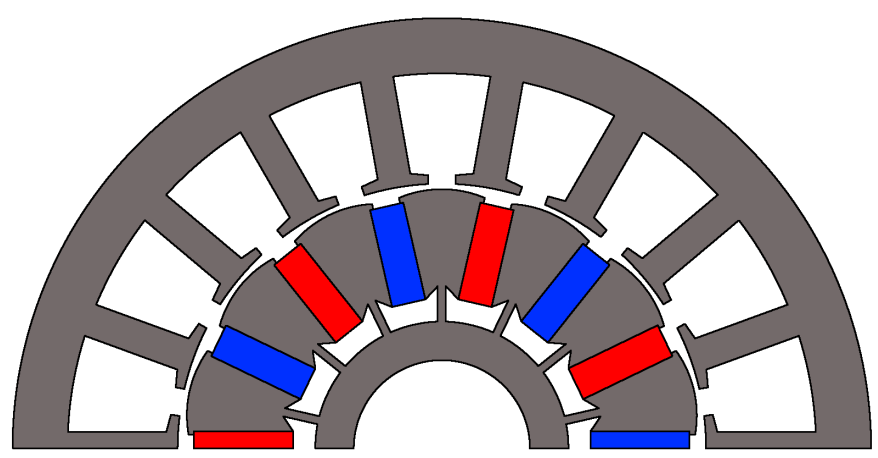

Fig. 2. Cross section of the PMSM with a spoke-type rotor.

TABLE I

MACHINE PARAMETERS

\begin{tabular}{ccc}
\hline Parameters & \multicolumn{2}{c}{ Values } \\
\hline outer diameter & 78 & $\mathrm{~mm}$ \\
rotor diameter & 47 & $\mathrm{~mm}$ \\
minimum airgap & 0.5 & $\mathrm{~mm}$ \\
phase windings & 84 & \\
phase resistance & 113.9 & $\mathrm{~m} \Omega$ \\
rated current & 17.3 & $\mathrm{~A}$ \\
rated torque & 2.1 & $\mathrm{Nm}$ \\
rated speed & 3000 & $\mathrm{rpm}$ \\
\hline
\end{tabular}




\section{B. Simulation Setup}

In order to compare the generated losses in the deltaand the star-connected machine, efficiency and loss maps are calculated. Therefore, the average flux linkages in d- and qaxis in dependence of d- and q-axis currents are calculated using Finite-Element-Analyses (FEA). Once the flux linkages are known, the electromagnetic torque for each combination of d- and q-axis currents is calculated by

$$
T_{\mathrm{em}}=\frac{3}{2} p \cdot\left(\psi_{\mathrm{d}} \cdot i_{\mathrm{q}}-\psi_{\mathrm{q}} \cdot i_{\mathrm{d}}\right),
$$

where $p$ denotes the number of pole pairs. For each operating point, defined by rotor speed and motor torque, a combination of $\mathrm{d}$ - and q-axis currents within the predefined limits of maximum phase current and line-to-line voltage is determined.

For motor operation, the loss model used for calculating the maps shown in Sec. IV is expressed by

$$
P_{\mathrm{sh}}=P_{\mathrm{el}}-P_{\mathrm{Cu}}-P_{\mathrm{Fe}}-P_{\mathrm{Fr}},
$$

where $P_{\mathrm{sh}}$ is the mechanical power at the motor shaft, $P_{\mathrm{el}}$ is the electrical power fed to the machine, $P_{\mathrm{Cu}}$ are the copper losses in the stator windings, $P_{\mathrm{Fe}}$ are the iron losses calculated with the Bertotti model [10] and $P_{\mathrm{Fr}}$ are friction losses, which are assumed to be the same for both machines. While operating as a generator the loss model becomes

$$
P_{\mathrm{el}}=P_{\mathrm{sh}}-P_{\mathrm{Cu}}-P_{\mathrm{Fe}}-P_{\mathrm{Fr}} .
$$

Due to the magnet arrangement in the rotor, the magnet losses are neglectable small, which is why they are not further investigated. A more detailed description of the used method for calculating efficiency and loss maps can be found in [11].

For the comparison of both machines, the nominal operating point of the delta-connected motor serves as a reference. In both models, the number of turns per phase is the same, which results in the same value for the stator resistance. For the star-connected machine this assumption leads to a line-to-line voltage, which is by a factor of $\sqrt{3}$ higher than the one for the delta-connected machine. For both machines, the flux linkage maps are calculated at the same phase currents. We choose maximum torque per ampere (MTPA) as operational strategy for both machines. In order to reach the same numerical accuracy for both FEA-models, the meshing and the time increment for each simulation step are the same. Consequently, the difference of generated losses between both machines, given in Sec. IV, only depends on the ZSCC.

\section{Simulation Results}

\section{A. Zero-Sequence Components}

In the nominal operating point, using MTPA as operational strategy, the currents in the d-and the q-axis were calculated as $i_{\mathrm{d}}=-1.05 \mathrm{~A}$ and $i_{\mathrm{q}}=14.1 \mathrm{~A}$. The amplitudes of harmonics in the flux linkage in this operating point are given in Table II for both machines in the stationary reference frame. Due to iron saturation a third harmonic occurs [3]. In the delta-connected machine, both the first and the third order harmonic have a smaller amplitude. In the rotating reference
TABLE II

AMPLITUdE OF HARMONICS IN THE FLUX LINKAGE FOR BOTH MACHINES IN THE NOMINAL OPERATING POINT (STATIONARY REFERENCE FRAME)

\begin{tabular}{|c|c|c|c|c|}
\hline & \multicolumn{4}{|c|}{ Flux Linkage (mVs) } \\
\hline Harmonic Order & $1^{\text {st }}$ & $3^{\text {rd }}$ & $5^{\text {th }}$ & $7^{\text {th }}$ \\
\hline Delta Connection & 15.66 & 0.06 & 0.19 & 0.02 \\
Star Connection & 15.82 & 0.56 & 0.05 & 0.02 \\
\hline
\end{tabular}

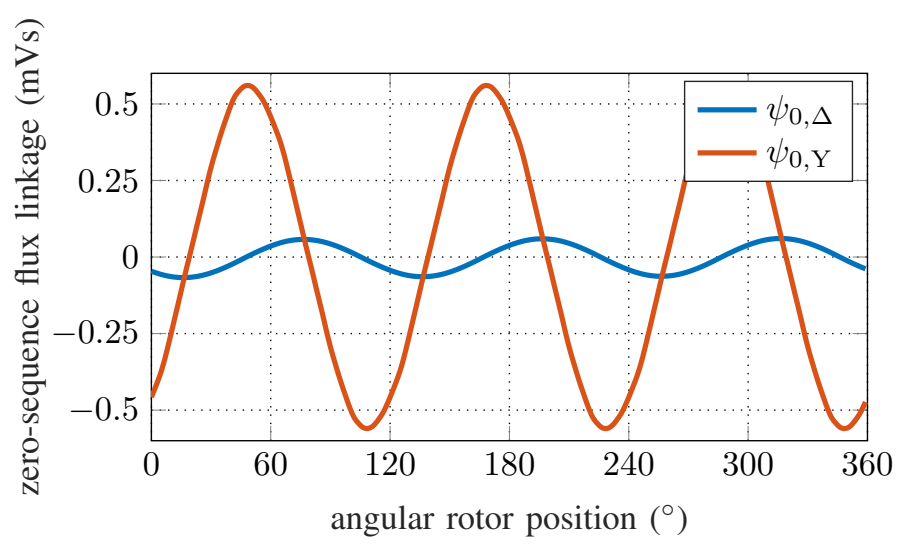

Fig. 3. Zero-sequence flux linkage component in the delta- and the starconnected machine at $n=3000 \mathrm{rpm}, i_{\mathrm{d}}=-1.05 \mathrm{~A}$ and $i_{\mathrm{q}}=14.1 \mathrm{~A}$.



Fig. 4. ZSCC in the delta- and the star-connected machine at $n=3000 \mathrm{rpm}$, $i_{\mathrm{d}}=-1.05 \mathrm{~A}$ and $i_{\mathrm{q}}=14.1 \mathrm{~A}$.

frame, a third order harmonic results in a zero-sequence component, which is for both machines depicted in Fig. 3. The comparison of both curves shows that the amplitude of the zero-sequence flux linkage in the star-connected machine is $0.56 \mathrm{mVs}$, whereas the amplitude only reaches $0.062 \mathrm{mVs}$ in the delta-connected machine. The reason for this fact is the ZSCC. Fig. 4 shows the ZSCC for both machines. In the star-connected machine a ZSCC cannot occur, whereas it has an amplitude of 3.6 A in the delta-connected machine. Due to Lenz's law, the ZSCC causes a magnetic field, which damps its cause. As a result, the amplitude of the zero-sequence flux linkage component is nearly ten times smaller in the delta-connected machine. In both machines, the zero-sequence components are dominated by the third order harmonic. 


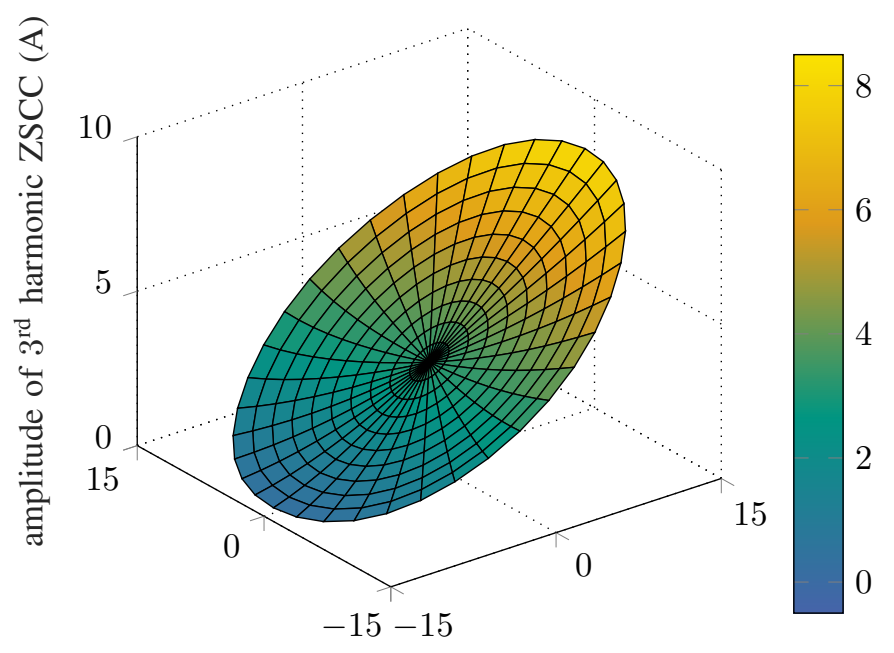

q-axis current (A)

d-axis current (A)

Fig. 5. Amplitude of the third order harmonic in the ZSCC in the deltaconnected machine in dependence of $\mathrm{d}$ - and q-axis currents at $n=3000 \mathrm{rpm}$.

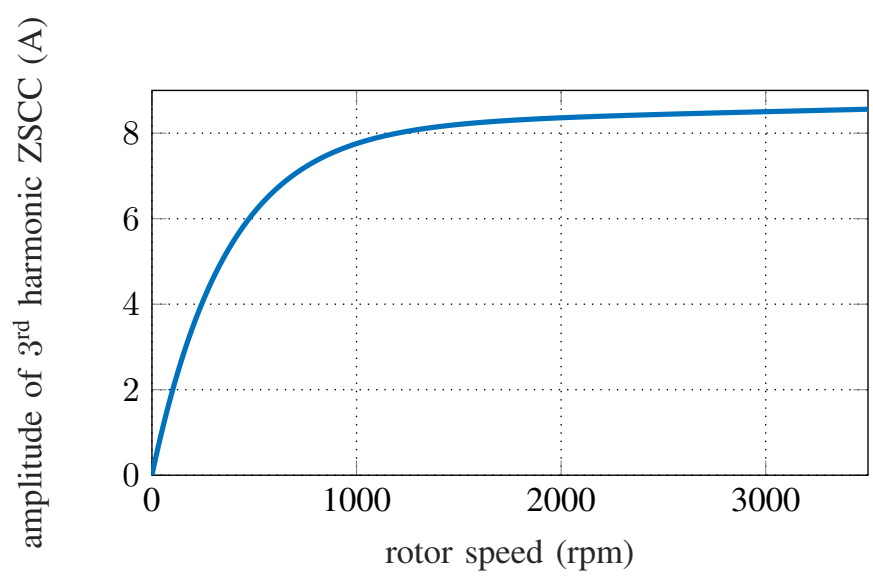

Fig. 6. Amplitude of the third order harmonic in the ZSCC in dependence of rotor speed $\left(i_{\mathrm{d}}=14.14 \mathrm{~A}, i_{\mathrm{q}}=0 \mathrm{~A}\right)$.

As a result, in the following only the third order harmonic in the ZSCC is regarded. Fig. 5 shows the amplitude of the third order harmonic in the ZSCC for the delta-connected machine in dependence of the $\mathrm{d}$ - and q-axis currents at a rotor speed of $3000 \mathrm{rpm}$. It is noticeable that the amplitude of the ZSCC mainly depends on the d-axis current and reaches a maximum of $8.5 \mathrm{~A}$ for nominal current in d-axis. In contrast to the d-axis current, the q-axis current has a minor effect on the ZSCC.

Besides the dependence on the $\mathrm{d}$ - and q-axis currents, the $\mathrm{ZSCC}$ is also dependent on the rotor speed. Fig. 6 exposes the ZSCC amplitude in dependence of the rotor speed at a d-axis current of $14.14 \mathrm{~A}$ and zero q-axis current. The amplitude of the ZSCC shows exponential behaviour and reaches a maximum of $8.56 \mathrm{~A}$ at $3500 \mathrm{rpm}$.

\section{B. Copper Losses}

For different rotor speeds, maps as shown in Fig. 5 were calculated, such that the ohmic losses generated by the ZSCC for each operating point can be calculated by

$$
P_{\mathrm{Cu}, 0}=\frac{3}{2} \cdot R \cdot \hat{i}_{0}^{2},
$$

where $\hat{i}_{0}$ denotes the amplitude of the third order harmonic in the ZSCC. Following, the total ohmic losses generated in the delta-connected machine can be determined by

$$
P_{\mathrm{Cu}}=P_{\mathrm{Cu}, 1}+P_{\mathrm{Cu}, 0},
$$

where $P_{\mathrm{Cu}, 1}$ are the copper losses generated by the first order current harmonic.

Fig. 7 depicts the additional copper losses caused by the ZSCC. For rotor speeds below $500 \mathrm{rpm}$ the additional losses mainly increase with the rotor speed. Contrarily, for rotor speeds above $1000 \mathrm{rpm}$ the additional losses mainly depend on the stator current. This behaviour corresponds to the results presented in Fig. 6. At the nominal operating point at a rotor speed of $3000 \mathrm{rpm}$ and a motor torque of $2.1 \mathrm{Nm}$ the additional copper losses reach a maximum of $1.97 \mathrm{~W}$. Compared to the ohmic losses generated by the first order current harmonic this equals an increase of $5.8 \%$. In the field-weakening region the losses generated by the ZSCC decrease, as the d-axis current is negative.

Over the whole operating range, the ohmic losses in the delta-connected machine reach a maximum of $36.14 \mathrm{~W}$ in the nominal operating point as shown in Fig. 8. In contrast to the delta-connected machine, the total copper losses in the starconnected machine are smaller over the whole operating range (see Fig. 9). In addition, the copper losses do not depend on the rotor speed. In the nominal operating point a maximum of $34.16 \mathrm{~W}$ is reached.

\section{Iron Losses}

As shown before, the amplitudes of the first and the third order harmonic in the flux linkage are smaller in the deltaconnected machine. Consequently, the flux linkages in the dand the q-axis are also smaller in the delta-connected machine.

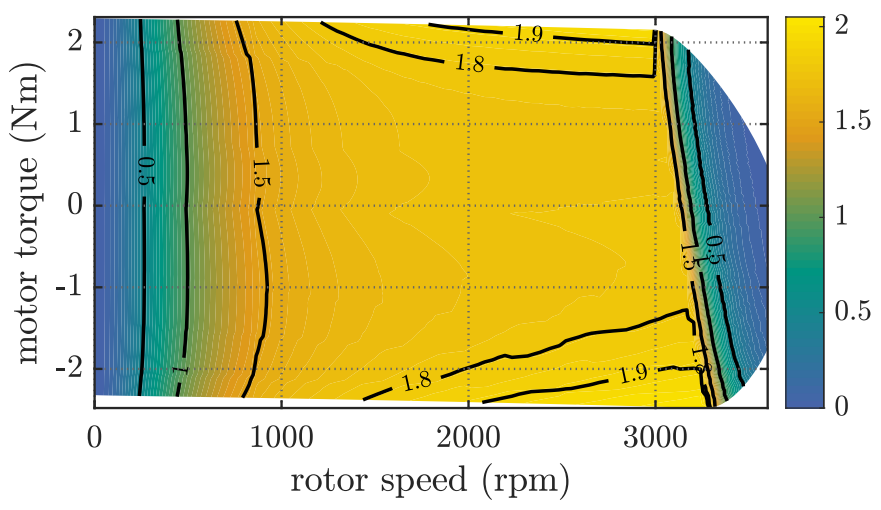

Fig. 7. Additional copper losses in the delta-connected machine over the operating range caused by ZSCC in $\mathrm{W}$. 


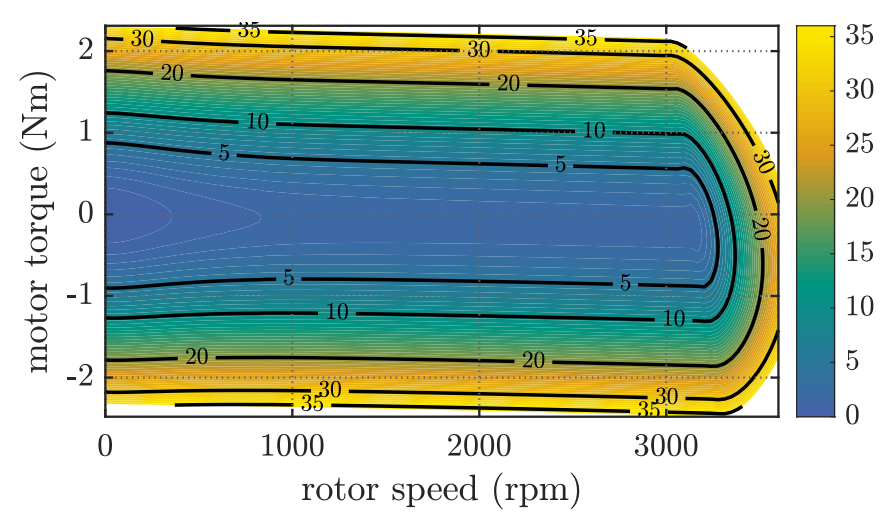

Fig. 8. Total copper losses in the delta-connected machine over the operating range in $\mathrm{W}$.

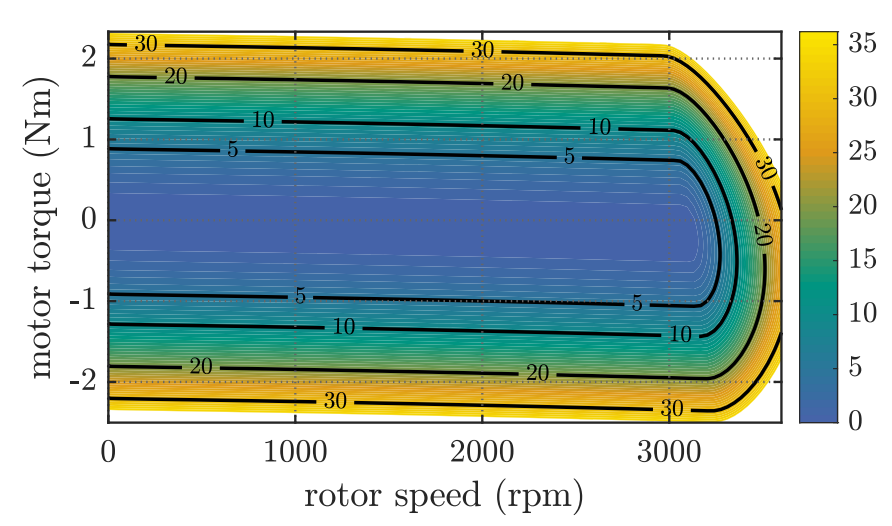

Fig. 9. Total copper losses in the star-connected machine over the operating range in $\mathrm{W}$.

In Fig. 10 and Fig. 11, the flux linkages in the d- and the q-axis over the angular rotor position are shown for both machines. In the delta-connected machine the average flux linkage in the d-axis is $15.37 \mathrm{mVs}$, whereas it is $15.52 \mathrm{mVs}$ in the starconnected machine. In the q-axis, the average flux linkages are $3 \mathrm{mVs}$ in the delta- and $3.06 \mathrm{mVs}$ in the star-connected machine. It is visible that the sixth order harmonic in the dand the q-axis flux linkage has a higher amplitude in the deltaconnected machine. This corresponds to the results given in Table II, which show that the amplitude of the fifth order harmonic in the stationary reference frame is bigger in the delta-connected machine.

The iron losses directly depend on the flux densities inside the machine. Therefore, the iron losses in the delta-connected machine are, in most parts of the operating range, $1 \%$ smaller than the ones in the star-connected machine (see Fig. 12). As depicted, the maximum difference of iron losses is $0.3 \mathrm{~W}$. Only in the field-weakening region, the iron losses in the deltaconnected machine are higher.

The total iron losses are shown in Fig. 13 for the deltaconnected machine. It can be seen, that they strongly depend on the rotor speed. In the nominal operating point the total iron losses reach a value of $24.37 \mathrm{~W}$.

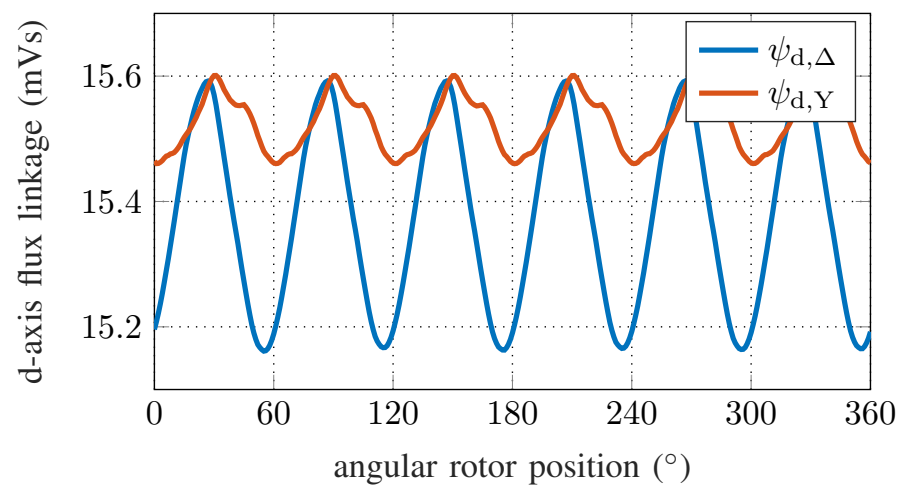

Fig. 10. Flux linkage in d-axis at $n=3000 \mathrm{rpm}, i_{\mathrm{d}}=-1.05 \mathrm{~A}$ and $i_{\mathrm{q}}=14.1 \mathrm{~A}$.

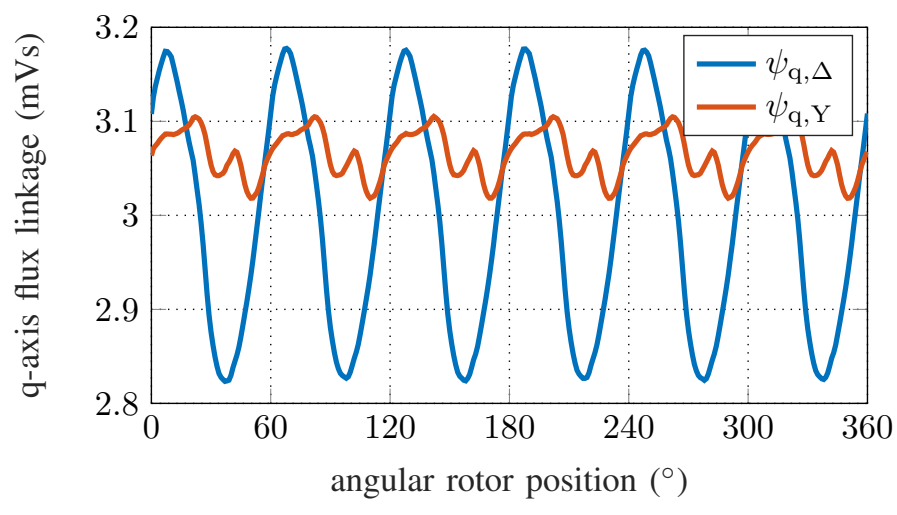

Fig. 11. Flux linkage in q-axis at $n=3000 \mathrm{rpm}, i_{\mathrm{d}}=-1.05 \mathrm{~A}$ and $i_{\mathrm{q}}=14.1 \mathrm{~A}$.

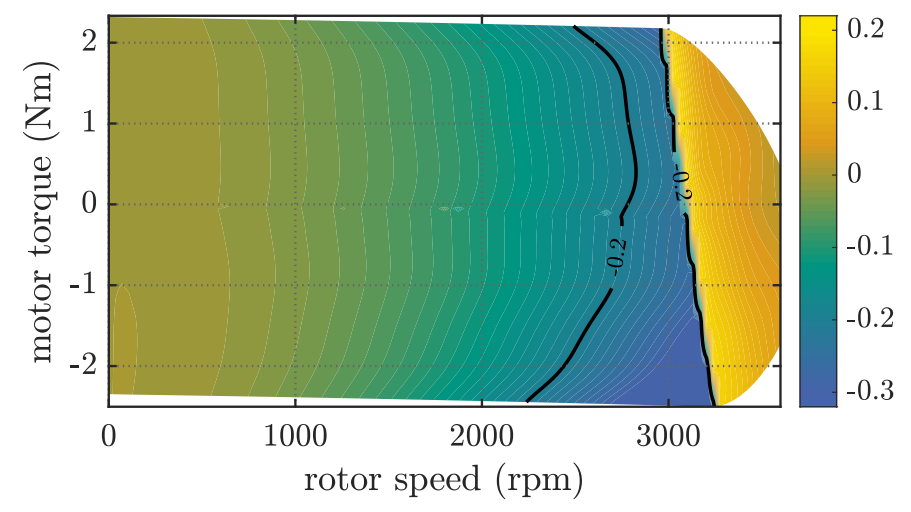

Fig. 12. Difference of iron losses between the delta- and the star-connected machine over the operating range in $\mathrm{W}$.

\section{Efficiency}

The efficiency $\eta$ of the machines is calculated by

$$
\eta=\frac{P_{\text {out }}}{P_{\text {out }}+P_{\text {loss }}}
$$

where $P_{\text {out }}$ is the output power. The additional copper losses in the delta-connected machine exceed the decrease of iron losses, which results in a lower efficiency (see Fig. 14). For rotor speeds below $1000 \mathrm{rpm}$ and a torque lower than $1 \mathrm{Nm}$, 




Fig. 13. Calculated iron losses using the Bertotti model in the delta-connected machine over the operating range in $\mathrm{W}$.



Fig. 14. Difference of efficiency between the delta- and the star-connected machine over the operating range in $\%$.

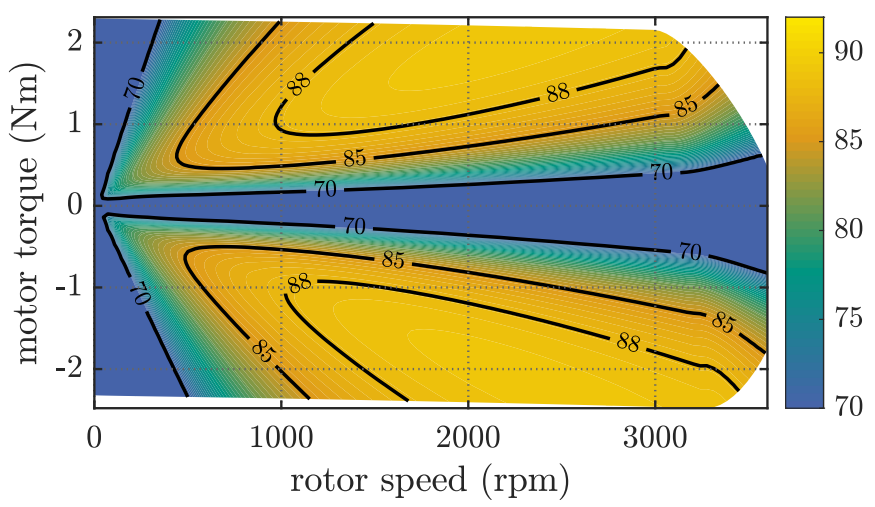

Fig. 15. Efficiency map of the delta-connected machine over the operating range in $\%$.

the efficiency of the delta-connected machine is up to $4 \%$ smaller. The efficiency of the delta-connected machine in the whole operating range is shown in Fig. 15. In the nominal operating point it has an efficiency of $88.9 \%$, while the starconnected machine has an efficiency of $89.5 \%$.

\section{CONCLusion ANd Future Work}

This paper compares the generated losses in a delta- and a star-connected PMSM with the same design in dependence of the ZSCC. It is shown that the amplitude of the ZSCC in the delta-connected machine strongly depends on the operating point of the machine. With higher saturation levels and rotor speeds, the amplitude of the ZSCC increases. In the deltaconnected machine the amplitude of the ZSCC is $3.6 \mathrm{~A}$ in the nominal operating point. The additional copper losses generated in this operating point equal $5.8 \%$ compared to those generated by the first order current harmonic. In contrast to the copper losses, the iron losses are, outside the fieldweakening region, smaller in the delta-connected machine. However, since the maximum difference of iron losses equals $0.3 \mathrm{~W}$, the overall efficiency of the delta-connected machine is smaller. In the nominal operating point the efficiency of the delta-connected machine is $0.6 \%$ smaller, while it is up to $4 \%$ smaller in other operating points. Since manufacturing tolerances were neglected in the simulations, an increase of the ZSCC is assumed for a real machine. Consequently, during design phases of a delta-connected PMSM the ZSCC has to be analysed in the whole operating range. Based on the presented results, star-connected stator windings in a PMSM are advantageous, regarding the generated copper losses and the efficiency of the machine.

For our future work, we aim to validate the simulation results on a test bench and apply the gained knowledge on the design and the control strategy of other types of PMSMs.

\section{REFERENCES}

[1] C. Dinca and U. Schfer, "Circulating currents of delta connected fractional slot machines for mass production," e \& i Elektrotechnik und Informationstechnik, vol. 132, no. 1, Feb. 2015, pp. 68-74.

[2] I. Coenen, C. P. Mboo, and K. Hameyer, "Statistical evaluation of manufacturing tolerances in electrical machines by simulation and measurement," in 4th International Conference on Power Engineering, Energy and Electrical Drives, Istanbul, Turkey, 2013, pp. 506-510.

[3] G. Müller, “Theorie elektrischer Maschinen," VCH Verlagsgesellschaft, 1995.

[4] S. Ding, J. Hang, H. Li, and Q. Wang,"Demagnetisation fault detection in PMSM using zero sequence current components," Electronics Letters, vol. 53, no. 3, Feb. 2017, pp. 148-150.

[5] E. Schmidt, M. Susic, and A. Eilenberger, "Design Studies on a Permanent Magnet Synchronous Machine With Y- and $\Delta$-Connected Stator Winding," IEEE Transactions on Magnetics, vol. 47, no. 5, May 2011, pp. 1042-1045

[6] F. J. T. E. Ferreira, A. M. Silva, S. M. A. Cruz, and A. T. De Almeida, Comparison of losses in star- and delta-connected induction motors with saturated core, in 2017 IEEE International Electric Machines and Drives Conference (IEMDC), Miami, FL, USA, 2017, pp. 1-8.

[7] J. R. Hendershot and T. J. E. Miller, "Design of brushless permanentmagnet machines," Motor Design Books, 2010.

[8] S. G. Lee, J. Bae, and W.-H. Kim, "A Study on the Maximum Flux Linkage and the Goodness Factor for the Spoke-Type PMSM," in IEEE Transactions on Applied Superconductivity, vol. 28, no. 3, Apr. 2018, pp. 1-5.

[9] K.-Y. Hwang, S.-B. Rhee, B.-Y. Yang, and B.-I. Kwon, "Rotor Pole Design in Spoke-Type Brushless DC Motor by Response Surface Method,' IEEE Transactions on Magnetics, vol. 43, no. 4, Apr. 2007, pp. 18331836.

[10] G. Bertotti, "General properties of power losses in soft ferromagnetic materials," IEEE Transactions on Magnetics, vol. 24, no. 1, Jan. 1988, pp. 621-630.

[11] P. Winzer, "Steigerung von Drehmoment und Wirkungsgrad bei Synchronmaschinen durch Nutzung der magnetischen Asymmetrie," Dissertation, Karlsruhe, June 2017. 